\title{
Identification of unknown genetically modified material admixed in conventional cotton seed and development of an event-specific detection method
}

\author{
Paschalis Akritidis \\ Institute of Agrobiotechnology \\ Centre for Research \& Technology Hellas \\ 6th Klm. Charilaou - Thermi Road \\ P.O. BOX 60361 GR - 57001 \\ Thermi, Thessaloniki, Greece \\ Tel: 302310498272 \\ Fax: 302310498270 \\ E-mail: paschalis@certh.gr

\section{Konstantinos Pasentsis} \\ Institute of Agrobiotechnology \\ Centre for Research \& Technology Hellas \\ 6th Klm. Charilaou - Thermi Road \\ P.O. BOX 60361 GR - 57001 \\ Thermi, Thessaloniki, Greece \\ Tel: 302310498274 \\ Fax: 302310498270 \\ E-mail:kpasents@certh.gr
}

\section{Athanasios S. Tsaftaris}

Institute of Agrobiotechnology

Centre for Research \& Technology Hellas

6th Klm. Charilaou - Thermi Road

P.O. BOX 60361 GR - 57001

Thermi, Thessaloniki, Greece

Tel: 302310498271

Fax: 30 2310-498270

E-mail: tsaft@certh.gr

Photini V. Mylona

Agricultural Research Center of Northern Greece

National Agricultural Research Foundation

Georgikis Sholis Avenue

57001 Thermi, Greece

Tel: 30 2310-471613

Fax: 30 2310-498270

E-mail: phmylona@nagref.gr

\section{Alexios N. Polidoros*}

Institute of Agrobiotechnology Centre for Research \& Technology Hellas

6th Klm. Charilaou - Thermi Road

P.O. BOX 60361 GR - 57001

Thermi, Thessaloniki, Greece

Tel: 302310498273

Fax: 302310498270

E-mail: alexios@certh.gr

Urls: www.certh.gr / www.nagref.gr

Financial support: This work was supported by a PENED grant (01E 4569$)$ awarded to A.N.P from the General Secretariat of Research and Technology $(\mathrm{GSRT})$ of Greece.

Keywords: event specific detection, genetically modified cotton, genome walking, GMO detection, Mon1445.

Abbreviations: CaMV: cauliflower mosaic virus

EU: European Union

GMO: genetically modified organism

NGO: non-governmental organization

PCR: polymerase chain reaction 
Entering the second decade of commercialization of biotech crops, the global area cultivated with transgenic plants constantly expands and national legislations in many countries, particularly in the European Union, require identification and labeling of genetically modified material in food and feed. We describe here a procedure for characterizing transgenic material of unknown origin present in conventional seed lots using a genome walking strategy for isolation and characterization of the junction between the inserted transgene construct and the host plant genomic DNA. The procedure was applied to transgenic cotton detected as adventitious or technically unavoidable presence in a conventional commercial cultivar. The structure of the isolated region revealed that the transgenic material derived from Monsanto's event 1445 transgenic cotton. Due to the random incorporation of the transgene into the host plant's genome, the sequence of the junction region obtained using the genome walking strategy, provided the means to develop an event-specific identification method without prior knowledge for the nature of the transformation event. Thus, we documented a methodology for developing an event-specific detection protocol even without prior knowledge of the genetic modification event.

In the last decade, many genetically modified cultivars have been commercialized and the global GM crop market constantly expands. Introduction of these new "high-tech" cultivars in the agricultural environment and their presence in food and feed products have been controversial issues. Transgenic plants have been hailed as a powerful way to increase agricultural productivity and to help alleviate hunger in underdeveloped nations (Borlaug, 2000), but also have raised concern over possible health, biosafety and environmental risks, pointing to the need for risk assessment and management (Haslberger, 2006). However, opposition to GM technology led by non-governmental organizations (NGOs) such as environmental groups and consumer associations often exaggerated the risks and spread fear to the public with the consequence that they are reluctant to adopt the new technology, especially in EU countries (Owens, 2003). Nevertheless, all nations have specific rules under which new biotech products are evaluated for these risks and approved before enter to the market. In EU particularly, authorization to release a GM organism in the environment is regulated by Directive 2001/18/EC (European Union, 2001), and only approved GM cultivars are allowed to be cultivated. Furthermore, the rules for placing into the market food or feed consisting of or containing GMO are stipulated by Regulations (EC) No 1829/2003 (European Union, 2003a) and (EC) No 1830/2003 (European Union, 2003b). EU legislation requires detection and monitoring of GMOs to enable safety assessment and enforce labeling, which leads to a high demand for reliable and easy to perform GMO detection and identification methods.

Among several available methodologies, PCR-based methods are the most sensitive, reliable and easy to perform (Anklam et al. 2002). Like all PCR techniques, GMO testing tools are designed to target and visualize the presence of specific transgene DNA fragments in plants and foods. Most of the early qualitative and semi-quantitative methodologies have been designed to target regulatory DNA sequences (promoters, terminators) common in many transgenic cultivars (Lipp et al. 1999; Tozzini et al. 2000). By testing for the presence of these fragments, especially the cauliflower mosaic virus (CaMV) $35 \mathrm{~S}$ promoter and the nos terminator from Agrobacterium tumefaciens that are common to most of the GMOs authorized by EU, the technique is versatile in screening for many different transgenic cultivars in one step, but has low specificity since it cannot discriminate between different GM cultivars harboring the same fragments. Moreover, the $35 \mathrm{~S}$ promoter and nos terminator are DNA fragments of naturally occurring plant pathogens and samples should be analyzed for naturally occurring infections, too (Wolf et al. 2000). These problems highlight the need to develop specific tests for each separate GM cultivar.

Detection methods based on gene targets that confer the trait to the transgenic cultivar or even better the constructspecific detection of junctions between regulatory elements and the target gene are more specific (Holst-Jensen et al. 2003). However, the EU law obligates market operators to differentiate GMOs at the level of the transformation event, and the "event" is meant to be an entity of higher specificity than the organism. This means that two apparently identical GMOs, identical organisms sharing the same set of transgene elements, could still be differentiated at the level of the transformation event (Lezaun, 2006). The only unique characteristic of each transformation event is the integration site into the recipient genome (Holst-Jensen et al. 2003). The junction between the transgene construct and the host genomic DNA (at both ends) can serve as event-specific identification marker related with the random integration of the transgene into the genome of the recipient plant.

Another issue pertinent to GMO detection is the restricted access to genetically modified material and information about transgene constructs. For the majority of GMOs authorized on a world wide basis there are currently no published primer pairs suitable for reliable identification. Sequence information describing the genetic modifications is usually kept confidential by biotech companies (HolstJensen et al. 2003), and when released their use is often restricted by patents. Certainly no information can be found for experimental GM organisms that are accidentally or intentionally introduced as admixture into a commercial cultivar. Since access to GM seed is difficult or prohibited, there is an ever increasing need for finding ways to

*Corresponding author 


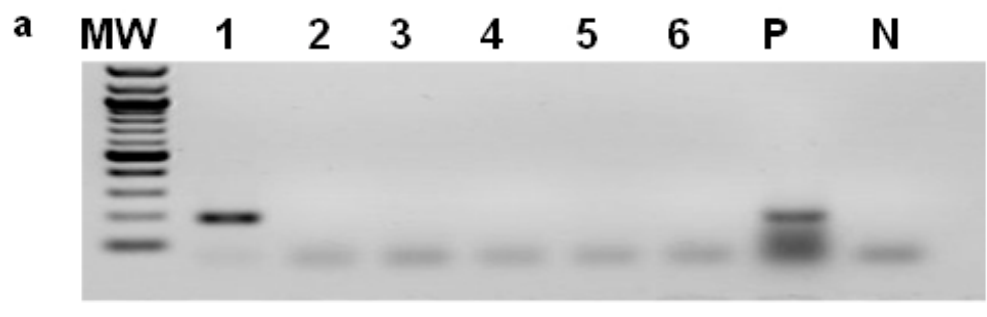

b
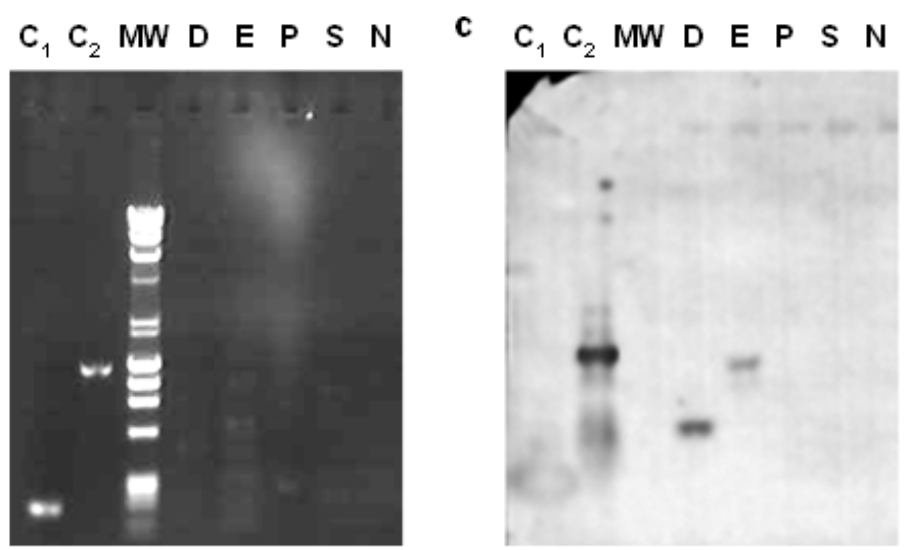

Figure 1. Identification of an individual GM cotton seedling using PCR and Southern hybridization.

(a) Identification of an individual GM cotton seedling. PCR was performed in each of the 6 plants (lanes 1-6) of a group tested positive for presence of the CaMV 35S promoter. Lane 1 shows the band from the sample containing the $35 \mathrm{~S}$ sequence (195bp) similar to the positive control $(\mathrm{P})$. MW is molecular weight DNA marker and $\mathrm{N}$ is negative (no template) control.

(b) PCR products using the primers $35 \mathrm{Spro} 3$ and AP1 on the libraries constructed with the Genome Walker kit (BD Biosciences, Palo Alto, USA) from DNA of the GM seedling using the restriction enzymes Dral, EcoRV, Pvull and Stul (lanes D, E, P, S respectively). No clear bands could be detected from the four libraries and the gel was transferred and hybridized with a CaMV 35S promoter -specific probe. $\mathrm{C}_{1}$ and $\mathrm{C}_{2}$ are positive PCR controls using GM cotton genomic DNA as template and the primers 35 Spro5/35Spro3 and 35 Spro5/NOS3 respectively and N is negative (no template) control. MW is the $\lambda$ Hind3- $\varphi \times 174$ molecular weight DNA marker.

(c) Southern hybridisation of a membrane produced after transfer of the PCR products shown on the gel of Figure $1 \mathrm{~b}$ with the CaMV 35S promoter -specific probe. Lanes are as in Figure 1b. Two bands were detected corresponding to the libraries D and E. Positive control $\mathrm{C}_{2}$ gave a strong hybridization signal and $\mathrm{C}_{1}$ was overexposed and produced a blurred diffused band.

overcome these obstacles.

A possible source of GM material is seeds or foods that are sent to diagnostic labs for testing. In this study, we used a genome walking strategy to identify the event-specific junction of the transgene with the recipient plant genomic DNA, in a cotton seed identified as GM from seed samples of a cotton cultivar screened positive for the presence of the $35 \mathrm{~S}$ promoter. Our results proved that the admixture concerned Monsanto's GM cotton event 1445 that is resistant to the herbicide glyphosate. Sequence information of the transgene incorporation site enabled us to design event-specific PCR primers suitable for GMO testing. The procedure can be easily adapted for use in any other plant.

\section{MATERIALS AND METHODS}

\section{Plant material}

A sample of cotton seeds from a conventional cotton cultivar sent to our lab for GMO screening was used in this study. The cotton cultivar Acala served as non-GM control. Seeds were planted in germination trays filled with
Terrahum $^{\mathrm{TM}}$ mix and perlite $(3: 1)$ and germinated at room temperature. Expanded cotyledons served as plant material for DNA extraction.

\section{PCR amplifications}

Amplification reactions were performed in a final volume of $25 \mu \mathrm{l}$ in the presence of $5 \mathrm{ng}$ of template DNA, 10 pmole of each primer, $0.2 \mathrm{mM}$ of each dNTP, 1 unit Taq polymerase (New England Biolabs, Ipswich, USA) and 2.5 $\mu 1$ 10X PCR buffer supplied by the manufacturer. The PCR was carried out using the PTC 200 thermocycler (MJ Research, Waltham, USA). All reactions were preceded by $4 \mathrm{~min}$ at $94^{\circ} \mathrm{C}$ denaturation and followed by $5 \mathrm{~min}$ at $72^{\circ} \mathrm{C}$ extension steps. Amplification reactions for $35 \mathrm{~S}$ detection, genome walk, non-GM cotton detection and event1445 detection, were performed in 35 cycles using the primers and at the conditions described in Table 1. Amplification products ( $5 \mu \mathrm{l}$ of each PCR) were electrophoresed onto $1.5 \%$ agarose (Cambrex, Berkshire, UK) gel in 1x TAE buffer, stained with ethidium bromide, and visualized by illumination with ultraviolet light. 


\section{DNA isolation and adapter ligation PCR}

Cotyledon samples were excised with a $6 \mathrm{~mm}$ diameter cork borer while seedlings remained in the tray and grew normally. Genomic DNA was extracted from fresh cotyledon material with the Qiagen DNeasy plant mini kit (Qiagen Inc, Chatsworth, USA) according the instructions. Cotton DNA tested 35S-positive was digested with the enzymes DraI, EcoRV, PvuII and StuI and adapters were ligated using the Universal Genome Walker Kit (BD Biosciences, Palo Alto, USA) according the instruction, for the construction of the libraries D, E, P and S, respectively. Primers and PCR conditions are listed in Table 1.

\section{Isolation, cloning and sequencing of the ligation PCR products}

PCR was performed for each library using either 35Spro5 or $35 \mathrm{Spro} 3$ and the adaptor primer AP1. All products were analyzed in agarose gels and subsequently transferred onto nylon membrane and hybridized with a 35S-specific probe. The probe was prepared by PCR using the 35 Spro5 and 35 Spro3 primers with template the pBI121 plasmid vector that harbors a fragment of the $35 \mathrm{~S}$ promoter. Positive bands were cut out of the gel using a scalpel, purified with the Nucleospin extract II kit (Macherey Nagel, Duren, Germany) and subsequently cloned into a plasmid vector using the TOPO TA cloning kit (Invitrogen, Paisley, UK). Clones were screened by hybridization with the $35 \mathrm{~S}$ probe and positive clones were sent for sequencing. Homology analysis of the amplified junction fragments was done by performing a BLAST search against the GenBank sequence database (Altschul et al. 1990).

GenBank accession number of the reported sequence: EU030419

\section{RESULTS}

\section{Identification of GM seeds admixed in a conventional cotton cultivar}

In a routine testing of conventional cotton seed lots for presence of GM material, a sample (consisting of about 500 homogenized seeds) tested positive for presence of the CaMV 35S promoter. This lot was the starting material for this study. Two thousand randomly selected seeds were planted individually and left to grow up to the cotyledon stage. Cotyledon samples were collected while leaving the seedling to continue growing and grouped into 40 groups of 50 samples. DNA was isolated independently from each group and PCR was performed to detect the presence of the $35 \mathrm{~S}$ promoter. One of the groups was positive. The plants from this group were further separated into 8 sub-groups. DNA isolation and detection of the $35 \mathrm{~S}$ promoter was repeated independently for each sub-group and the individual GM seedling was identified repeating the 35Sspecific PCR one more time in the positive sub-group (Figure 1a). Thus, performing 54 independent DNA isolations and PCRs we were able to identify, in a short time, a single GM seed out of 2000, without any prior information about its transgenic nature.

\section{Characterization of the transgene-host plant DNA junction}

Based on the $35 \mathrm{~S}$ sequence of the GM plant we tried to identify flanking DNA regions. DNA from this plant (that was still growing) was isolated and used for the construction of four libraries (D, E, P and S) to enable genome walking. PCR reactions were performed using a $35 \mathrm{~S}$ promoter-specific primer and the AP1 adaptor primer on each library. PCR products using the $35 \mathrm{Spro} 3$ primer (Table 1) were analyzed in agarose gel 1.5\% (Figure 1b).

Table 1. Primer sequences and PCR conditions.

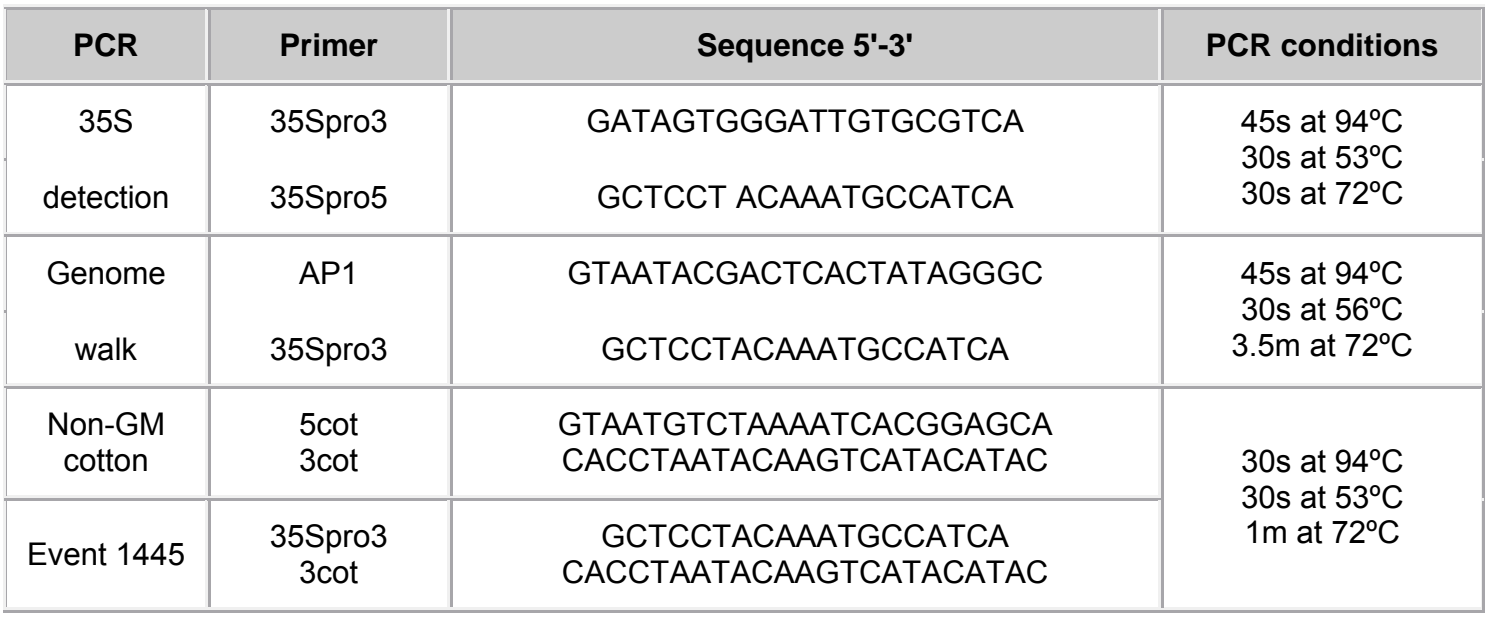


Consequently they were transferred on nylon membrane and hybridized with a $35 \mathrm{~S}$ probe (Figure 1c). The hybridization was positive for libraries $\mathrm{D}$ and $\mathrm{E}$, indicating the presence of the $35 \mathrm{~S}$ sequence in both bands, which were purified, cloned to plasmid vectors and sequenced.

The sequence of the $1100 \mathrm{bp}$ larger fragment (E library) included that of the smaller fragment (D library) and was further analyzed. BLAST searches of the GenBank (nucleotide collection $\mathrm{nr} / \mathrm{nt}$ at $\mathrm{NCBI}$ ) revealed homology with CaMV 35S between positions 1-237 and with ori-V between 250-554. The remaining 546bp identified no homologous fragment in the same GenBank database and probably was cotton genomic sequence. The $1100 \mathrm{bp}$ sequence of this fragment was deposited in the GenBank and is accessible under the accession number EU030419. Sequencing of the PCR product of the P library at the other end of $35 \mathrm{~S}$ in the transgene construct determined the sequence of the nptII gene (data not shown).

The most widely cultivated GM cotton cultivars are Monsanto's Roundup Ready ${ }^{\circledR}$ (event 1445) and Bollgard ${ }^{\circledR}$ (event 531). According to the BATS report (Bruderer and Leitner, 2003) both cultivars have been produced using constructs that contain nptII under the control of $35 \mathrm{~S}$ promoter preceded by ori-V. Information in the safety assessment of Roundup Ready ${ }^{\circledR}$ cotton event 1445 (http://www.monsanto.com/monsanto/content/sci_tech/prod safety/roundup_cotton/pss.pdf) and a pertinent publication (Nida et al. 1996) indicated that this insert contains the CoMVb promoter region, cp4 epsps, aad, nptII, and a portion of ori-V coding regions. This structure resembles the one identified in the transgene material we examined. Further search for information in a patent regarding event 1445 (patent no 6,740,488, US Patent Office) revealed an identical sequence (designated sequence 8 in the patent) spanning the junction of the transgene with the host DNA up to position 681 of the isolated sequence. This was confirmed searching the GenBank patent (pat) database at NCBI and conclusively suggested that the material under study was originated from event 1445. A map was accordingly designed (Figure 2a) where the transgene construct and the flanking cotton DNA fragments are shown and a solid double arrow indicates the fragment identified in this study whilst the dotted double arrows indicate sequences reported in the Monsanto patent mentioned above. Novel sequence information in this study extends the 3' flanking region of event 1445 by $419 \mathrm{bp}$ and is enough for the design of event-specific primers that are not restricted by any patent.

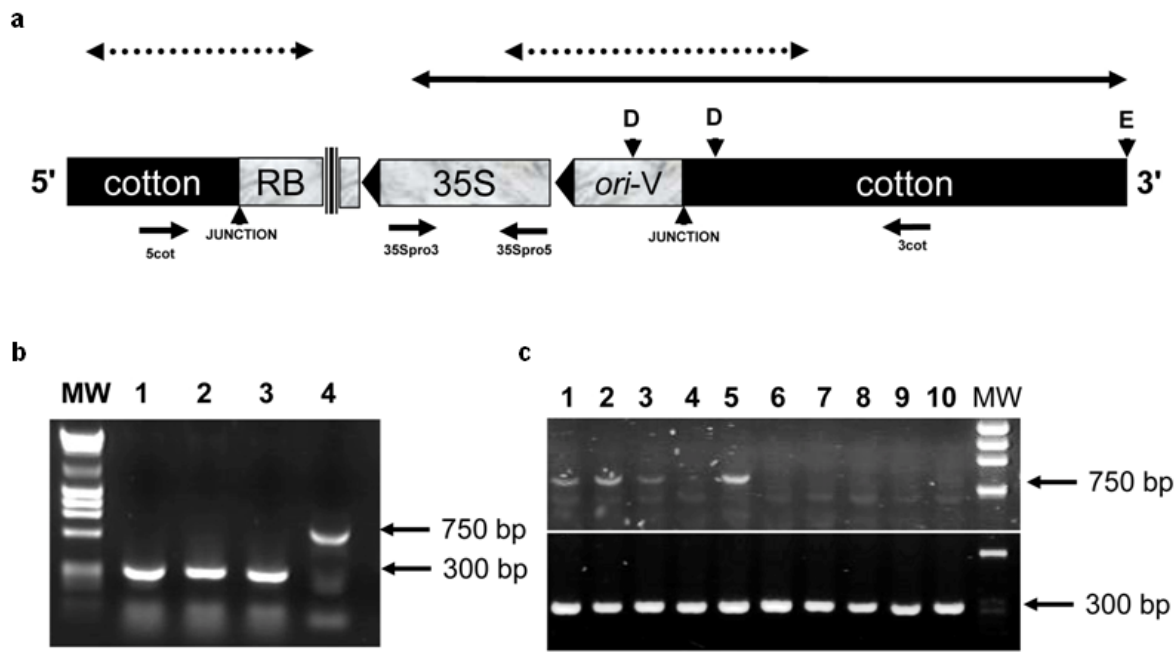

Figure 2. Genetic map and event-specific PCR detection of transgenic cotton event 1445.

(a) Genetic map of part of the transgene construct and the flanking cotton DNA fragments of the GM plant. The ori-V fragment and the CaMV 35S promoter region of the construct are shown and arrowheads indicate the direction towards the 3' end of the elements. Vertical lines indicate discontinuous map drawing. The solid double arrow above the map indicates the fragment identified in this study while the dotted double arrows indicate sequences reported in the Monsanto patent regarding cotton event PV-GHGT07(1445) and compositions and methods for detection thereof (patent no 6,740,488, US Patent Office). D and E represent the restriction enzyme sites Dral, and EcoRV, respectively. Junction sites are indicated by arrowheads below the map of the construct and positions of primers are indicated with arrows pointing towards the 3' end of each primer.

(b) Event-specific PCR detection of cotton event 1445. Agarose gel analysis of PCR products with the primers 3 cot and 5 cot, using as template three different varieties of conventional cotton (lanes 1,2,3) and with the primers 35Spro3 and 3 cot and template transgenic event 1445 cotton (lane 4). MW is molecular weight marker.

(c) Event-specific PCR detection of cotton event 1445 in seed samples tested positive for presence of the CaMV 35S promoter. Upper panel: PCR products of a reaction performed with the 35 Spro3 and 3cot primer pair that could amplify the event 1445 specific 750 bp band in samples 1, 2, 3 and 5. In lane 1 the sample that was used as starting material of the study was loaded. Lower panel: PCR products of a reaction performed with the 5 cot and 3 cot primer pair that could amplify a cotton specific 300 bp band in all samples. MW is molecular weight marker. 


\section{Event specific detection of the Mon1445 cotton}

In order to prepare an event specific test for cotton Mon1445 we designed a specific primer at the 3'flanking region (primer $3 \mathrm{cot}$ ), amplifying a sequence of $750 \mathrm{bp}$ in combination with primer 35 Spro3. For a negative control identifying non GM cotton genomic DNA we designed a primer on genomic DNA flanking the 5'end of the transgene from sequence information in the patent no $6,740,488$ (US Patent Office). Thus we designed the 5 cot primer amplifying a sequence of $\sim 300 \mathrm{bp}$ when applied with 3 cot on non-GM cotton template.

The test was performed in three non-GM samples and the isolated transgenic sample. Existence of Mon1445 cotton was confirmed by the presence of a 750bp PCR product, whereas existence of non-GM cotton was confirmed by the presence of a $\sim 300 \mathrm{bp}$ band (Figure $2 \mathrm{~b}$ ). In order to validate the developed test we examined whether it could be successfully applied in the original seed sample which was used as staring material in this study, as well as in other cotton seed samples screened positive for presence of the $35 \mathrm{~S}$ promoter. Results showed that the event 1445 -specific 750 bp band could be amplified from the original 35Spositive sample (Figure 2c, lane 1) as well as in three additional samples (lanes 2, 3, 5) out of the 10 35S-positive samples examind. A cotton-specific $300 \mathrm{bp}$ band could be amplified in all samples indicating that presence of the GM material was due to admixture in the conventional seed lots (Figure 2c).

\section{DISCUSSION}

In this study we presented an experimental strategy for developing an event-specific GMO detection test without prior knowledge of the transgene introduced to the host plant genetic material. The only prerequisite of the procedure is access to a sample tested positive for presence of an element commonly used in transgenic cultivars. Beginning with a cotton seed sample that was found to be positive for presence of the $35 \mathrm{~S}$ promoter we identified a single GM plant. With no further information about the specific event, we used a genome walking strategy to identify sequences flanking the $35 \mathrm{~S}$ promoter. These sequences were used to search GenBank and other databases and acquired information led to recognition that the GM material derived from Monsanto's cotton event 1445. With this strategy we characterized part of the construct that was introduced into the host plant genome and the junction between transgene and recipient genome. It should be mentioned that no information was available for the cotton genomic sequence identified in this study. This is, to the best of our knowledge, the first reported proof of event-specific identification of unknown transgenic material adventitiously present in conventional cultivars.

Development of PCR-based event-specific GMO detection procedures for known GM events has been described in several relevant reports. A range of genome walking strategies such as anchored PCR, ligation-mediated PCR and inverse PCR have been used to identify junction sequences and develop event specific tests for a number of transgenic cultivars including Roundup-Ready soybean (Windels et al. 2001), Mon810 MaisGard maize (Holck et al. 2002), Bt11 maize (Ronning et al. 2003), Starlink maize (Windels et al. 2003), Mon863 maize (Yang et al. 2005b), NewLeaf potato (Cote et al. 2005), T25 maize (Collonnier et al. 2005), Bt11, Bt176, GA21 maize and GT73 canola (Taverniers et al. 2005). An event specific detection method for Mon1445 has also been described (Yang et al. 2005a). However, these researchers used GM material provided by Monsanto and primers designed according to the relevant Monsanto patent information. Our study differs from the one mentioned above in that we used unknown admixed GM material to develop an event-specific detection protocol, which resulted in better knowledge of the transgene incorporation region since the junction sequence was characterized further into the plant genome and allowed the design of the new primer 3 cot and an event 1445 -specific test. We also demonstrated that the developed test was able to discriminate event 1445 -positive samples among several 35S-positive samples, offering validation of its specificity in detecting the event in unintended admixtures. Thus, we provided evidence for the feasibility of developing an event specific test from a sample containing unknown GM material that has been screened positive for a frequently used sequence (35S promoter in this case) in GMO constructs. This is the only prerequisite for the described procedure and there is a possibility that it cannot be met if screening of suspected samples proves negative for commonly used elements. This can be dealt with use of microarray technology in the initial screening. Several attempts have been made to take advantage of the vast amount of sequences that can be immobilized in microarrays for GMO detection (Anklam et al. 2002; Leimanis et al. 2006; Nesvold et al. 2005) and commercial kits are now available (e.g. Eppendorf ${ }^{\circledR}$ DualChip ${ }^{\circledR}$ GMO microarray; U-Vision Biotech DNA Microarray-Based GMO Detection Kit). Use of a microarray containing an updated repertoire of genetic elements currently used in plant transformation will provide a better opportunity to identify GM material in an initial screening and can provide sequence information for primer design to enable an anchored-PCR based genome walking.

Public attitude to a system with strict rules for authorization of GMO cultivation and traceability of GM material in the food chain has been positive (Tsioumani, 2004). Successful implementation of an effective GM traceability strategy that is based on accurate detection of specific GM events as outlined in the present study will enable enforcement of the labeling legislation, which may also contribute to consumer confidence in food security, providing the right of informed choice, particularly in the current climate of consumer distrust in the products of agricultural biotechnology. 


\section{REFERENCES}

ALTSCHUL, Stephen F.; GISH, Warren; MILLER, Webb; MYERS, Eugene W. and LIPMAN, David J. Basic local alignment search tool. Journal of Molecular Biology, October 1990, vol. 215, no. 3, p. 403-410.

ANKLAM, Elke; GADANI, Ferrucio; HEINZE, Petra; PIJNENBURG, Hans and VAN DEN EEDE, Guy. Analytical methods for detection and determination of genetically modified organisms in agricultural crops and plant-derived food products. European Food Research and Technology, January 2002, vol. 214, no 1, p. 3-26.

BORLAUG, Norman E. Ending world hunger. The promise of biotechnology and the threat of antiscience zealotry. Plant Physiology, October 2000, vol. 124, no. 2, p. 487490.

BRUDERER, S and LEITNER, K. Genetically Modified Crops: molecular and regulatory details. Agency BATS. July 2003. Portable Document Format. Available from Internet: http://www.bats.ch/gmo-watch/GVOreport140703.pdf.

COLLONNIER, Cecile; SCHATTNER, Alexandra; BERTHIER, Georges; BOYER, Francine; COUEPHILIPPE, Geraldine; DIOLEZ, Annick; DUPLAN, Marie N.; FERNANDEZ, Sophie; KEBDANI, Naima; KOBILINSKY, Andre; ROMANIUK, Marcel; De BEUCKELEER, Marc; De LOOSE, Marc; WINDELS, Pieter and BERTHEAU, Yves. Characterization and event specific-detection by quantitative real-time PCR of T25 maize insert. Journal AOAC International, March 2005, vol. 88 , no. 2, p. 536-546.

COTE, Marie J.; MELDRUM, Allison J.; RAYMOND, Phillippe and DOLLARD, Cheryl. Identification of genetically modified potato (Solanum tuberosum) cultivars using event specific polymerase chain reaction. Journal of Agricultural and Food Chemistry, August 2005, vol. 53, no. 17 , p. 6691-6696.

European Union. Directive 2001/18/EC of the European Parliament and of the Council of 12 March 2001 on the deliberate release into the environment of genetically modified organisms and repealing Council Directive 90/220/EEC. Official Journal of the European Communities, April 2001, vol. 44, L106, p.1-38. Portable Document Format. Available from Internet: http://eurlex.europa.eu/LexUriServ/site/en/oj/2001/1_106/1_ 10620010417en00010038.pdf. ISSN 0378-6978.

European Union. Regulation (EC) No. 1829/2003 of the European Parliament and of the Council of 22 September 2003 on genetically modified food and feed Official Journal of the European Union, October 2003a, vol. 46, L268, p.123. Portable Document Format. Available from Internet: http://eurlex.europa.eu/LexUriServ/site/en/oj/2003/1_268/1_ 26820031018en00010023.pdf. ISSN 1725-2555.
European Union. Regulation (EC) No. 1830/2003 of the European Parliament and of the Council of 22 September 2003 concerning the traceability and labelling of genetically modified organisms and the traceability of food and feed products produced from genetically modified organisms and amending Directive 2001/18/EC. Official Journal of the European Union, October 2003b, vol. 46, L268, p.24-28. Portable Document Format. Available from Internet:

http://eurlex.europa.eu/LexUriServ/site/en/oj/2003/1_268/1_ 26820031018en00240028.pdf . ISSN 1725-2555.

HASLBERGER, Alexander G. Need for an 'Integrated Safety Assessment' of GMOs, linking food safety and environmental considerations. Journal of Agricultural and Food Chemistry, May 2006, vol. 54, no. 9, p. 3173-3180.

HOLCK, Askild; VAITILINGOM, Marc; DIDIERJEAN, Luc and RUDI, Knut. 5'-Nuclease PCR for quantitative event-specific detection of the genetically modified Mon810 MaisGard maize. European Food Research and Technology, May 2002, vol. 214, no. 5, p. 449-453.

HOLST-JENSEN, Arne, RONNING, Sissel B.; LOVSETH, Astrid and BERDAL, Knut G. PCR technology for screening and quantification of genetically modified organisms (GMOs). Analytical and Bioanalytical Chemistry, April 2003, vol. 375, no. 8, p. 985-993.

LEIMANIS, Serge; HERNÁNDEZ, Marta; FERNÁNDEZ, Sophie; BOYER, Francine; BURNS, Malcolm; BRUDERER, Shirin; GLOUDEN, Thomas; HARRIS, Neil; KAEPPELI, Othmar, PHILIPP, Patrick; PLA, Maria; PUIGDOMENECHE, Pere; VAITILINGOM, Marc; BERTHEAU, Yves and REMADE Jose. A Microarraybased Detection System for Genetically Modified (GM) Food Ingredients. Plant Molecular Biology, May 2006, vol. 61, no. 1-2, p. 123-139.

LEZAUN, Javier. Creating a new object of government: making genetically modified organisms traceable. Social Studies of Science, August 2006, vol. 36, no. 4, p. 499-531.

LIPP, M; ANKLAM, E; BRODMANN, P; PIETSCH, K and PAUWELS, J. Results of an interlaboratory assessment of a screening method of genetically modified organisms in soy beans and maize. Food Control, December 1999, vol. 10 , no. 6 , p. 379-383.

NESVOLD, Harvard; KRISTOFFERSEN, Anja B.; HOLST-JENSEN, Arne and BERDAL, Knut G. Design of a DNA chip for detection of unknown genetically modified organisms (GMOs). Bioinformatics, May 2005, vol. 21, no. 9, p. 1917-1926.

NIDA Debbie L.; KOLACZ Kathryn H.; BUEHLER, Robert E.; DEATON, Randy D.; SCHULER, William R.; ARMSTRONG, Toni A.; TAYLOR, Mary L.; EBERT, Christine C.; ROGAN, Glennon J.; PADGETTE, Stephen R. and FUCHS, Roy L. Glyphosate-Tolerant Cotton: 
Genetic Characterization and Protein Expression. Journal of Agricultural and Food Chemistry, July 1996, vol. 44, no. 7, p. 1960-1966.

OWENS, Susan R. Feeding prejudice. EMBO Reports, March 2003, vol. 4, no. 3, p. 229-232.

RONNING, Sissel B.; VAITILINGOM, Marc; BERDAL, Knut G. and HOLST-JENSEN, Arne. Event specific realtime quantitative PCR for genetically modified Bt11 maize (Zea mays). European Food Research and Technology, April 2003, vol. 216, no. 4, p. 347-354.

TAVERNIERS, Isabel; WINDELS, Pieter; VAITILINGOM, Marc; MILCAMPS, Anne; VAN BOCKSTAELE, Eric; VAN DEN EEDE, Guy and DE LOOSE, Marc. Event-specific plasmid standards and realtime PCR methods for transgenic Bt11, Bt176, and GA21 maize and transgenic GT73 canola. Journal of Agricultural and Food Chemistry, April 2005, vol. 53, no. 8, p. 30413052 .

TOZZINI, Alejandro C; MARTINEZ, Carolina M; LUCCA, Florencia M; ROVERE, Cecilia V; DISTEFANO, Ana J; DEL VA, Mariana and HOPP, Esteban H. Semiquantitative detection of genetically modified grains based on CaMV35S promoter amplification. Electronic Journal of Biotechnology, August 2000, vol. 3, no. 2 [cited date]. Available from Internet: http://www.ejbiotechnology.info/content/vol2/issue3/full/3/ index.html. ISSN 0717-3458.

TSIOUMANI, Elsa. Genetically modified organisms in the EU: public attitudes and regulatory developments. Review of European Community \& International Environment Law, November 2004. vol. 13, no. 3, p. 279-288.

WINDELS, Pieter; TAVERNIERS, Isable; DEPICKER, Anne; VAN BOCKSTAELE, Eric and DE LOOSE, Marc. Characterisation of the Roundup Ready soybean insert. European Food Research and Technology, August 2001, vol. 213, no. 2, p. 107-112.

WINDELS, Pieter; BERTRAND, Sophie; DEPICKER, Anne; MOENS, William; Van BOCKSTAELE, Eric and DE LOOSE, Marc. Qualitative and event specific PCR realtime detection methods for StarLink maize. European Food Research and Technology, March 2003, vol. 216, no. 3, p. 259-263.

WOLF, Christina; SCHERZINGER, Margitta; WURZ, Andreas; PAULI, Urs; HUBNER, Philipp and LUTHY, Jurg. Detection of cauliflower mosaic virus by the polymerase chain reaction: testing of food components for false-positive 35S-promoter screening results. European Food Research and Technology, March 2000, vol. 210, no. 5, p. 367-372.

YANG, Litao; PAN, Aihu; ZHANG, Kewei; YIN, Changsong; QIAN, Bingjun; CHEN, Jianxiu; HUANG,
Cheng and ZHANG, Dabing. Qualitative and quantitative PCR methods for event-specific detection of genetically modified cotton Mon1445 and Mon531. Transgenic Research, December 2005a, vol. 14, no.6, p. 817-831.

YANG, Litao; XU, Songci; PAN, Aihu; YIN, Changsong; ZHANG, Kewei; WANG, Zhenying; ZHOU, Zhigang and ZHANG, Dabing. Event specific qualitative and quantitative polymerase chain reaction detection of genetically modified Mon863 maize based on the 5'transgene integration sequence. Journal of Agricultural and Food Chemistry, November 2005b, vol. 53, no. 24, p. $9312-$ 9318. 